\title{
BEST PRACTICE: PENDEKATAN "COLLA-COOP” UNTUK MENINGKATKAN KOMPETENSI MANAJERIAL KEPALA SEKOLAH MELALUI INSTRUMEN PKKS DI SDN 005 CINTA DAMAI TAHUN 2020
}

\author{
Tugiwan Supriyanto, S.Pd. \\ Kepala SDN 005 Cinta Damai, Kecamatan Tapung Hilir, Kabupaten Kampar \\ supriyantotugiwan@gmail.com
}

\begin{abstract}
ABSTRAK
Best Practices ini bertujuan untuk meningkatkan kompetensi kepala sekolah melalui Instrumen PKKS. Kepala Sekolah dituntut memiliki kompetensi manajerial dalam melaksanakan tupoksinya memimpin sekolah, yang setiap tahun diukur dan dinilai dengan instrumen PKKS. Tupoksi kepala sekolah sebagaimana diatur dalam Permendikbud nomor 28 tahun 2010 tentang Guru yang diberi tugas tambahan, meliputi: 1. Merencanakan Program sekolah; 2. Melaksanakan Rencana Kerja sekolah; 3. Melaksanakan pengawasan dan evaluasi; 4. Menjalankan kepemimpinan sekolah; dan 5. Menerapkan sistem informasi sekolah. Standar kompetensi kepala sekolah sebagaimana diatur dalam Permendikbud nomor 13 tahun 2007 tentang Standar Kompetensi Kepala Sekolah, melipiti 5 Kompetensi: Kepribadian, Manajerial, Kewirausahaan, Supervisi, dan Sosial. Berdasarkan regulasi Permendikbud di atas, dalam instrumen PKKS dijabarkan menjadi 6 dimensi kompetensi: 1. Kepribadian dan Sosial; 2. Kepemimpinan Pembelajaran; 3. Pengembangan Sekolah; 4. Manajemen Sumber Daya; 5. Kewirausahaan; dan 6. Supervisi Pembelajaran. Hasil PKKS pada tahun pertama perlu ditingkatkan hasilnya pada tahun kedua, dengan indikator belum terpenuhinya bukti fisik yang dituntut saat penilaian. Oleh karena itu kepala sekolah memandang perlu melakukan kegiatan bekerja sama kepada kepala sekolah lain agar tupoksi manajerial dapat berjalan sesuai standar yang telah ditetapkan. Best Practices ini dilakukan dalam rangka meningkatkan kompetensi manajerial kepala sekolah menggunakan Instrumen PKKS. Kegiatan yang dilakukan dalam Best Practices ini adalah sebagai berikut: 1. Pengarahan dan penjelasan awal (Review) tentang tupoksi dan kompetensi Kepala Sekolah sesuai standar; 2. Bedah instrumen PKKS; 3. Workshop berbagi tugas menyusun dokumen bukti fisik yang harus dilakukan kepala sekolah, yang dilaksanakan bertahap dengan tahapan penyusunan draf, presentasi, revisi dan finalisasi yang dilakukan berdaur ulang; 4. Pengumpulan hasil draf akhir dan disitribusi komulatif, dan 5. Review program masing-masing sekolah. Pelaksanan Best Practices berjalan baik, karena setiap kepala sekolah merasa kegiatan tersebut wajib dilakukannya dan hasil produk kegiatan merasa harus dimiliki. Kendala kecil terjadi berkaitan dengan kemampauan IT kepala sekolah, namun dapat diatasi dengan baik. Hasil akhir kegiatan Best Practices ini adalah setiap kepala sekolah memiliki produk draf program sekolah dan wawasan tentang tugas manajerial seperti tuntutan instrumen PKKS, yang harus dikembangkan lebih lanjut di sekolah masing-masing.
\end{abstract}

Kata kunci: Pendekatan, Colla-Coop, Kompetensi, Manajerial, PKKS

\section{PENDAHULUAN}

\section{Latar Belakang}

Dalam Sistem Pendidikan Nasional, Kepala Sekolah memiliki fungsi strategis dalam peningkatan mutu proses pembelajaran peserta didik. Fungsi tersebut terkait dengan tanggung jawab kepala sekolah dalam hal pembinaan Guru maupun Tenaga Kependidikan. Pembinaan tersebut diharapkan berdampak pada peningkatan kualitas pembelajaran di kelas dan kualitas pendidikan nasional secara umum. Kualitas sekolah erat kaitannya dengan kualitas kepemimpinan kepala sekolah dengan asumsi bahwa kualitas sekolah akan meningkat jika kemampuan kepala sekolah ditingkatkan.

Kepala Sekolah merupakan salah satu tenaga kependidikan yang memegang peran strategis dalam meningkatkan profesionalisme guru, kepala sekolah, dan 


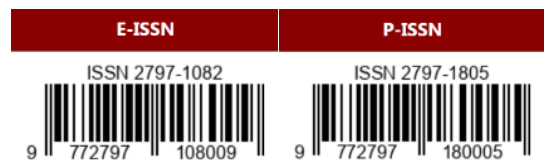

mutu pendidikan di sekolah. Usaha peningkatan kemampuan kepala sekolah telah menjadi komitmen Pemerintah yang dituangkan dalam PermenPAN dan RB Nomor 21 Tahun 2010. Pada Peraturan tersebut, khususnya pada pasal 14, secara eksplisit dijelaskan bahwa salah satu kegiatan kepala sekolah adalah menyusun, melaksanakan, dan menilai program pembelajaran dan pelatihan profesional para guru.

Kepala sekolah memiliki peran yang sangat strategis dalam peningkatan kualitas pendidikan terutama berkaitan dengan upaya pengembangan sekolah. Peraturan Menteri Pendidikan dan Kebudayaan (Permendikbud) Nomor 13 Tahun 2007 tentang Standar Kepala Sekolah/Madrasah menetapkan dimensi kompetensi yang harus dimiliki oleh kepala sekolah dalam menjalankan tupoksinya. Tupoksi kepala sekolah agar dapat dijalankan dengan baik, maka kompetensi kepala sekolah harus senantiasa ditingkatkan. Peningkatan kompetensi kepala sekolah dapat diperoleh melalui Pengembangan Keprofesian Berkelanjutan (PKB). Permendikbud Nomor 28 Tahun 2010 menjelaskan bahwa kepala sekolah harus melakukan pengembangan keprofesian secara berkelanjutan dan berbasis kebutuhan yang disebut PKB kepala sekolah. Konsekuensi dari jabatan kepala sekolah merupakan guru sebagai profesi, diperlukan suatu sistem pembinaan dan pengembangan terhadap profesi guru secara terprogram dan berkelanjutan. Pengembangan keprofesian berkelanjutan (PKB) merupakan salah satu kegiatan yang dirancang untuk mewujudkan terbentuknya guru dan kepala sekolah yang profesional.

Dengan diberlakukannya PermenPanRB Nomor 16 tahun 2009 yang secara efektif berlaku sejak tanggal 1 Januari 2013, maka kinerja guru dan guru yang mendapat tugas tambahan sebagai kepala sekolah dilakukan setiap tahun yang hasilnya dikonversi ke dalam angka kredit guru, sehingga kinerja guru sangat menentukan pengembangan karier seorang guru. Oleh karena itu, seorang kepala sekolah wajib melakukan PKB sebagai guru maupun sebagai kepala sekolah, agar kinerjanya baik memenuhi standar minimal yang diprasyaratkan.

Kepala sekolah sebagai tenaga profesional mempunyai fungsi, peran, dan kedudukan yang sangat penting di bidang manajerial. Kinerja kepala sekolah diukur dan dinilai setiap tahun dengan instrumen kinerja kepala sekolah (PKKS), yang dikembangkan berdasarkan tupoksi kepala sekolah sesuai dalam Permendikbud Nomor 28 tahun 2010. Kemudian disempurnakan pada Permendikbud Nomor 15 tahun 2018. Untuk itu, seorang kepala sekolah memiliki kemampuan manajerial yang memadai, agar sekolah yang dikelolanya dapat berhasil dengan baik. Maka kepala sekolah berkewajiban untuk dapat membina dan membimbing para guru di bidang manajerial.

Berdasarkan temuan hasil penilaian kinerja kepala sekolah (PKKS) tahun 2019 di SDN 005 Cinta Damai menunjukkan bahwa kemampuan manajerial kepala sekolah masih perlu untuk ditingkatkan, yang ditandai dengan indikator bahwa dokumen bukti fisik sebagai hasil kinerja kepala sekolah yang dituntut harus ada dalam PKKS pada umumnya belum dimiliki sepenuhnya, dan ada pula yang program telah dilaksanakan namun bukti pelaksanaan belum terdokumentasikan dengan baik, bahkan ada pula yang sama sekali belum memiliki dokumen sebagai bukti fisik yang diukur dalam kinerja kepala sekolah dengan instrumen PKKS. Maka kepala sekolah perlu melakukan upaya untuk mengatasi masalah 
tersebut, agar kepala sekolah dapat memenuhi tugasnya sesuai standar kinerja yang ditentukan.

Berdasarkan permasalahan yang dihadapi kepala sekolah, perlu dilakukan kegiatan dengan pendekatan collaborativecooperative yang diharapkan sebagai solusi untuk menyelesaikan masalah yang dihadapi kepala sekolah. Pendekatan collaborativecooperative yang akan digunakan sebagai solusi untuk mengatasi masalah yang dihadapi, oleh kepala sekolah selanjutnya istilah collabotative-cooperatif disebut dalam laporan Best Practices ini sebagai pendekatan "Colla-Coop"

\section{Rumusan Masalah}

Berdasarkan permasalahan tersebut di atas, maka rumusan masalah dalam Best Practices ini adalah:

a. Bagaimanakah pendekatan "Colla-Coop" dapat membantu kepala sekolah meningkatkan kemampuan manajerial?

b. Bagaimana perubahan kemampuan manajerial kepala sekolah setelah diterapkan pendekatan "Colla-Coop"?

\section{Tujuan dan Manfaat}

Tujuan pelaksanaan Best Practices ini adalah untuk mengetahui peningkatan kemampuan manajerial kepala sekolah melalui Instrumen penilaian kinerja dengan pendekatan "Colla-Coop".

Pendekatan "Colla-Coop" dalam Best Practices ini bermanfaat:

1) Bagi Kepala Sekolah: membantu meningkatkan kemampuan dan mempermudah dalam melaksanakan tugas manajerial dalam mengelola sekolah yang dipimpinnya.

2) Bagi Pengawas: keberhasilan Best Practices ini dapat dipergunakan sebagai model monitoring dalam pembinaan kepala sekolah binaannya.

\section{KAJIAN PUSTAKA \\ Kemampuan Manajerial}

Setiap kepala sekolah wajib memiliki kemampuan manajerial, yang merupakan kemampuan mengelola sekolah yang dipimpinnya, agar berdaya guna dan berhasil guna. Esensi kemampuan manajerial adalah menyangkut tentang pengelolaan dan administrasi sekolah, yaitu semua hal yang termasuk pendukung keterlaksanaan proses pembelajaran. Dengan demikian fokus supervisi manajerial ini ditujukan pada pelaksanaan bidang garapan manajemen sekolah, yang antara lain meliputi: (a) manajemen kurikulum dan pembelajaran, (b) kesiswaan, (c) sarana dan prasarana, (d) ketenagaan, (e) keuangan, (f) hubungan sekolah dengan masyarakat, dan (g) layanan khusus (Pusbangtendik Kemdikbud, 2012: 5).

\section{Penilaian Kinerja Kepala Sekolah (PKKS) Penilaian kinerja kepala sekolah/madrasah merupakan salah satu langkah yang dapat ditempuh untuk mengidentifikasi kebutuhan akan} pengembangan keprofesian berkelanjutan, sebagai balikan yang dapat dimanfaatkan sebagai pijakan dalam melakukan refleksi kinerja, dan juga dapat digunakan untuk kepentingan pemberian imbalan, promosi, maupun sanksi bagi guru yang bersangkutan (Depdiknas, 2010: 27). Instrumen PKKS yang digunakan untuk menilai kenierja kepala sekolah adalah sesuai lampiran Permendikbud Nomor 15 tahun 2018.

\section{Pendekatan "Colla-Coop" dalam Pendampingan Kepala Sekolah melalui Instrumen PKKS}




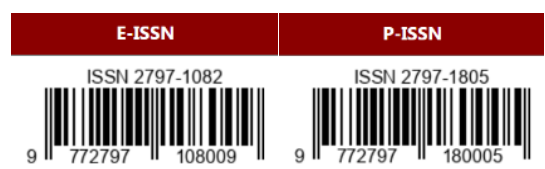

"Colla-Coop" merupakan singkatan dari Collaborative-Cooperative yang berarti bekerja sama (John M Echols dan Hassan Shadily: 1990: 124, 147). Pendekatan "CollaCoop" merupakan pendekatan yang memanfaatkan kolaborasi dan kerjasama antar kepala sekolah melalui forum Kelompok Kerja Kepala Sekolah (KKKS), untuk memecahkan bersama-sama permasalahan yang dijumpai dalam penyelenggaraan dan pengelolaan sekolah, sehingga setiap kepala sekolah dapat memperoleh solusi pemecahan masalah yang dihadapi dengan baik.

\section{PEMBAHASAN MASALAH}

\section{Hasil Kegiatan Sebelumnya}

Pelaksanaan tupoksi manajerial kepala sekolah sebelum adanya aplikasi PKKS menunjukkan belum maksimal, yang ditandai dengan adanya indikator Permendikbud nomor 13 tahun 2007 dan Permendikbud nomor 35 tahun 2010 belum terwujud sepenuhnya. Program sekolah pada umumnya terlaksana belum didukung oleh perencanaan dan pengadministrasian dengan baik. Administrasi pengelolaan sekolah masih mengacu pada pola lama sebelum kedua Permendikbud itu lahir. Padahal instrumen PKKS yang akan dipakai (berdasarkan Permendikbud Nomor 15 tahun 2018) untuk menilai kinerja kepala sekolah didasarkan pada kedua regulasi tersebut. Dengan demikian masalah yang muncul adalah timbulnya kesenjangan antara tuntutan yang harus ada dengan kenyataan yang ada. Dalam instrumen PKKS kepala sekolah dituntut memiliki dokumen bukti fisik pengelolaan manajerial yang berkaitan dengan program sekolah, yang pada umumnya dokumen tersebut belum semuanya dimiliki. Untuk itu Best Practices ini dipandang perlu dilakukan oleh kepala sekolah, agar kepala sekolah segera dapat memenuhi tuntutan kinerjanya agar memenuhi standar yang telah ditetapkan, yaitu memiliki program sekolah serta pelaksanaan progran terdokumentasi dengan baik.

\section{Strategi Pemecahan Masalah}

Masalah yang dihadapi adalah: "Langkah apakah yang perlu dilakukan kepala sekolah, agar kepala sekolah dapat memenuhi kompetensi manajerial dan memenuhi tuntutan kinerja dalam PKKS?"

Strategi pemecahan masalah untuk menyelesaikan masalah tersebut adalah kepala sekolah perlu segera melakukan kegiatan untuk meningkatkan kompetensi manajerial kepala sekolah menggunakan instrumen PKKS dengan menggunakan pendekatan "Colla-Coop".

\section{Alasan pemilihan strategi pemecahan masalah}

Pemilihan strategi pemecahan masalah tersebut dengan pendekatan "CollaCoop" adalah berdasarkan argumentasi, bahwa kompetensi manajerial kepala sekolah mencakup aspek yang sangat kompleks dalam penyelenggaraan sekolah. Jika seorang kepala sekolah memikirkan dan menyelesaikan sendiri komponen-komponen yang termuat dalam tugas manajerial yang harus dilakukan, akan terasa berat beban kerjanya. Apalagi instrumen PKKS menuntut dokumen bukti fisik sebagai bukti hasil kerja kepala sekolah. Dengan pendekatan "Colla-Coop" kepala sekolah melalui pertemuan KKKS, dapat mengerjakan dan memikirkan bersama-sama dengan kepala sekolah lain semua aspek dan komponen yang termuat dalam tugas manajerial yang dituntut instrumen PKKS. Dengan demikian tugas yang kompleks tersebut menjadi ringan, dan kualitas pekerjaan yang dikerjakan bersama-sama hasilnya akan lebih baik dan lebih sempurna. 


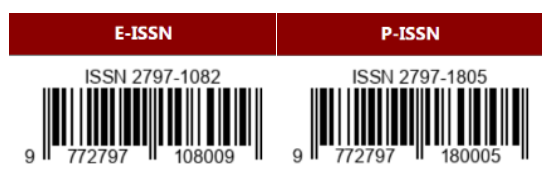

Pertimbangan lain lebih efektif dalam pembinaan dan pembimbingan. Hal tersebut dapat diselesaikan melalui kegiatan kolektif kepala sekolah dalam forum KKKS.

\section{Deskripsi strategi pemecahan masalah}

Pendekatan "Colla-Coop" untuk meningkatkan kompetensi manajerial kepala sekolah menggunakan instrumen PKKS. Pendekatan "CollaCoop" adalah pendekatan collaboratif dan cooperatif, yaitu pendekatan pembimbingan dan pendampingan kepala sekolah yang berbasis kolaborasi dan bekerja bersama-sama untuk menyelesaikan masalah dan untuk mencapai tujuan bersama. Karena kompleksnya komponen manajerial yang dikelola kepala sekolah, kolaborasi dan kerja sama antar sesama kepala sekolah sangat diperlukan. Kebersamaam dalam memecahakan masalah dan pekerjaan, akan membuat pekerjaan yang banyak dan berat akan terasa ringan dengan tidak mengesampingkan kualitasanya. Kolaborasi dan kerjasama antar kepala sekolah dilakukan melalui kegiatan kolektif dalam forum Kelompok Kerja Kepala Sekolah (KKKS).

\section{Tahapan Operasional Pelaksanaan}

Tahapan pelaksanaan Best Practices pendekatan "Colla-Coop" ini adalah sebagai berikut:

1) Pengarahan dan penjelasan awal (Review) tentang tupoksi dan kompetensi Kepala Sekolah sesuai standar pada Permendikbud nomor 13 tahun 2007 dan Permendikbud nomor 35 tahun 2010.

2) Bedah instrumen PKKS (berdasar Permendiknasbud Nomor 15 tahun 2018);

3) Workshop berbagi tugas menyusun dokumen bukti fisik yang harus dilakukan kepala sekolah, yang dilaksanakan bertahap dengan tahapan penyusunan draf, presentasi, revisi dan finalisasi yang dilakukan berdaur ulang;

4) Pengumpulan hasil draf akhir dan disitribusi komulatif kepada setiap kepala sekolah.

5) Review oleh setiap kepala sekolah disesuaikan dengan program masingmasing sekolah.

6) 3. Pembahasan Pelaksanaan Best Practices dengan Pendekatan "CollaCoop"

Pelaksanaan Best Practices dilakukan selama 4 bulan dari bulan Agustus 2020 sampai Nopember 2020. Pelaksanaan dilakukan sebanyak 7 kali pertemuan, dengan rincian sebagai berikut:

\section{1) Pertemuan 1 pada tanggal 23 Agustus 2020}

Pertemuan pertama ini agendanya adalah penjelasan pengarahan (review) tentang standar kompetensi dan tupoksi kepala sekolah sesuai Permendikbud nomor 13 tahun 2007 dan Permendikbud nomor 35 tahun 2010 .

2) Pertemuan 2 pada tanggal 6 September 2020

Pertemuan kedua agendanya adalah bedah instrumen PKKS (berdasarkan Permendikbud Nomor 15 tahun 2018), yang bertujuan memberikan pemahaman dan wawasan kepala sekolah tentang aspek dan komponen yang termuat dalam instrumen PKKS. Dengan demikian kepala sekolah akan menyadari apa yang harus dilakukan dan bukti fisik apa yang dituntut harus ada dalam PKKS sebagai bukti fisik hasil kinerja sebagai kepala sekolah. Dengan pemahaman dan wawasan yang telah dimiliki kepala sekolah, kepala sekolah untuk melakukan refleksi apakah 
aspek dan komponen yang termuat dalam instrumen PKKS sudah dilakukan dan didokumentasikan sebagai bukti fisik kinerjanya, terdeteksi ada 16 macam dokumen manajerial kepala sekolah. Hasil refleksi dibahas bersama, kesimpulannya kepala sekolah pada umumnya kegiatan yang ada pada instrumen PKKS sudah ada yang dilakukan dan masih ada yang belum dilaksanakan, serta sebagian besar dokumen bukti fisiknya belum dibuat. Kesimpulan tersebut ditindaklanjuti dengan kesepakatan bersama untuk menyusun draf program, dengan berbagi tugas antar kepala sekolah dalam forum K3S. Tiap program dibuat oleh 2-3 orang. Hasilnya dipresentasikan secara bergiliran, sehari 4 program.

3) Pertemuan 3 pada tanggal 20 September 2020

Presentasi dan revisi program 1-4

4) Pertemuan 4 pada tanggal 3 Oktober 2020 Presentasi dan revisi program 5-8

5) Pertemuan 5 pada tanggal 17 Oktober 2020

Presentasi dan revisi program 9-12

6) Pertemuan 6 pada tanggal 3 Nopember 2020

Presentasi dan revisi program 13-16

7) Pertemuan 7 pada tanggal 17 Nopember 2020

Pengumpulan draf final dan pendistribusian komulatif.

8) Setiap kepala sekolah mereview draf program disesuaikan dengan kebutuhan program sekolah masing-masing.

\section{Hasil Pelaksanaan Best Practices dengan Pendekatan "Colla-Coop"}

Hasil dari kegiatan ini adalah setiap kepala sekolah memiliki 16 draf program sekolah sesuai instrumen PKKS untuk dikembangkan lebih lanjut di sekolah masing- masing. 16 dokumen draf program tesebut adalah sebagai berikut:

\begin{tabular}{|c|c|c|c|c|c|}
\hline \multirow{2}{*}{ No. } & \multirow{2}{*}{$\begin{array}{c}\text { Nama } \\
\text { Program }\end{array}$} & \multirow{2}{*}{$\begin{array}{c}\text { No. } \\
\text { Indikator } \\
\text { PKKS }\end{array}$} & \multicolumn{3}{|c|}{ Kelengkapan Dokumen } \\
\hline & & & $\begin{array}{l}\text { Prog } \\
\text { ram }\end{array}$ & $\begin{array}{l}\text { Evaluasi } \\
\text { Program }\end{array}$ & $\begin{array}{l}\text { Tindak } \\
\text { Lanjut }\end{array}$ \\
\hline \multirow[t]{6}{*}{ I } & Manajerial & 1.1 & & & \\
\hline & $\begin{array}{l}\text { Perencanaan } \\
\text { program } \\
\text { sekolah }\end{array}$ & 1.1 .1 & V & V & V \\
\hline & $\begin{array}{l}\text { Pengelolaan } \\
\text { Standar } \\
\text { Nasional } \\
\text { Pendidikan }\end{array}$ & 1.1 .2 & V & V & V \\
\hline & $\begin{array}{l}\text { Pengawasan } \\
\text { dan Evaluasi }\end{array}$ & 1.1 .3 & $\mathrm{~V}$ & V & V \\
\hline & $\begin{array}{l}\text { Kepemimpi- } \\
\text { nan Sekolah }\end{array}$ & 1.1 .4 & V & V & V \\
\hline & $\begin{array}{l}\text { Sistem } \\
\text { Informasi } \\
\text { Manajemen } \\
\text { Sekolah }\end{array}$ & 1.1 .5 & $\mathrm{~V}$ & V & V \\
\hline \multirow[t]{4}{*}{ II } & $\begin{array}{l}\text { Pengemba- } \\
\text { ngan Kewira- } \\
\text { usahaan }\end{array}$ & 1.2 & & & \\
\hline & $\begin{array}{l}\text { Perencanaan } \\
\text { Pengemba- } \\
\text { ngan Kewira- } \\
\text { usahaan }\end{array}$ & 1.2 .1 & V & V & $\mathrm{V}$ \\
\hline & $\begin{array}{l}\text { Pelaksanaan } \\
\text { Pengemba- } \\
\text { ngan Kewira- } \\
\text { usahaan }\end{array}$ & 1.2 .2 & V & V & V \\
\hline & $\begin{array}{l}\text { Evaluasi } \\
\text { Pengemba- } \\
\text { ngan Kewira- } \\
\text { usahaan }\end{array}$ & 1.2 .3 & $\mathrm{~V}$ & V & $\mathrm{V}$ \\
\hline \multirow[t]{4}{*}{ III } & $\begin{array}{l}\text { Supervisi } \\
\text { Guru dan } \\
\text { Tendik }\end{array}$ & 1.3 & & & \\
\hline & $\begin{array}{l}\text { Perencanaan } \\
\text { Supervisi } \\
\text { Guru dan } \\
\text { Tendik }\end{array}$ & 1.3 .1 & V & V & V \\
\hline & $\begin{array}{l}\text { Pelaksanaan } \\
\text { Supervisi } \\
\text { Guru dan } \\
\text { Tendik }\end{array}$ & 1.3 .2 & $\mathrm{~V}$ & V & $\mathrm{V}$ \\
\hline & $\begin{array}{l}\text { Evaluasi } \\
\text { Supervisi } \\
\text { Guru dan } \\
\text { Tendik }\end{array}$ & 1.3 .3 & $\mathrm{~V}$ & V & $\mathrm{V}$ \\
\hline
\end{tabular}




\begin{tabular}{|c|c|c|c|c|c|}
\hline \multirow{2}{*}{ No. } & \multirow{2}{*}{$\begin{array}{c}\text { Nama } \\
\text { Program }\end{array}$} & \multirow{2}{*}{$\begin{array}{c}\text { No. } \\
\text { Indikator } \\
\text { PKKS }\end{array}$} & \multicolumn{3}{|c|}{ Kelengkapan Dokumen } \\
\hline & & & $\begin{array}{l}\text { Prog } \\
\text { ram }\end{array}$ & $\begin{array}{l}\text { Evaluasi } \\
\text { Program }\end{array}$ & $\begin{array}{l}\text { Tindak } \\
\text { Lanjut }\end{array}$ \\
\hline IV & $\begin{array}{l}\text { Pengemba- } \\
\text { ngan Keprofe- } \\
\text { sian Berkelan- } \\
\text { jutan }\end{array}$ & 3 & V & V & $\mathrm{V}$ \\
\hline & $\begin{array}{l}\text { Pengemba- } \\
\text { ngan Diri }\end{array}$ & 3.1 & V & V & V \\
\hline & $\begin{array}{l}\text { Publikasi } \\
\text { Ilmiah }\end{array}$ & 3.2 & V & V & V \\
\hline & Karya Inovatif & 3.3 & $\mathrm{~V}$ & V & V \\
\hline $\mathrm{V}$ & $\begin{array}{l}\text { Kegiatan } \\
\text { Penunjang }\end{array}$ & 4 & V & V & V \\
\hline & $\begin{array}{l}\text { Pelaksanaan } \\
\text { Kegiatan } \\
\text { Penunjang }\end{array}$ & 4.1 & & & \\
\hline
\end{tabular}

\section{Dampak Pelaksanaan Best Practices} dengan Pendekatan "Colla-Coop"

Pelaksanaan Best Practices dengan Pendekatan "Colla-Coop" memiliki dampak praktis sebagai berikut:

1) Setiap kepala sekolah memahami standar kompetensinya sebagai kepala sekolah dan berupaya terus-menerus untuk mencapainya sesuai standar.

2) Setiap kepala sekolah memiliki wawasan tentang tupoksinya sebagai kepala sekolah, sehingga dapat melaksanakan tupoksinya dengan baik.

3) Setiap kepala sekolah dapat menyusun program sekolah yang dipimpinnya dan melaksanakannya dengan baik.

4) Setiap kepala sekolah dapat mendokumentasikan hasil kerjanya dengan baik sebagai bukti fisik.

5) Setiap kepala sekolah siap untuk menghadapi penilaian kinerja kepala sekolah dengan baik.

\section{SIMPULAN DAN REKOMENDASI Simpulan}

Dari hasil Best Practices yang telah dipaparkan di atas, dapat disimpulkan bahwa pendekatan "Colla Coop" sangat efektif untuk meningkatkan kompetensi manajerial kepala sekolah.

\section{Rekomendasi}

Hasil pendekatan "Colla-Coop" menunjukkan bahwa pendekatan ini sebagai solusi untuk meningkatkan kompetensi manajerial kepala sekolah. Maka pendekatan "Colla-Coop" ini dapat diterapkan juga oleh kepala sekolah lain untuk menyelesaikan permasalahan yang sejenis.

\section{DAFTAR PUSTAKA}

John M Echols dan Hassan Shadily. Kamus Inggris- Indonesia. Jakarta: PT Gramedia

Kemdikbud. 2011. Pedoman Pelaksanaan Permendikbud Nomor 28 tahun 2010. Jakarta: BPSDMPK-PMP 2010. Permendikbud Nomor 35 tahun 2010 tentang Petunjuk Teknis Pelaksanaan Jabatan Fungsional Guru dan Angka Kreditnya.

Kemdikbud. 2012. Dimensi Supervisi Manajerial. Jakarta; Pusbangtendik BPSDSMPK-PMP

MenegPan. 2009. Permennegpan dan RB Nomor 16 tahun 2009 tentang Jabatan Fingsional Guru dan Angka Kreditnya. Unifah Rosyidi, dkk. 2012. Pedoman Kegiatan Pengembangan Keprofesian Berkelanjutan (PKB) dan Angka Kreditnya. Jakarta: BPSDMPK-PMP Depdikbud. 